

\section{POLÍTICAS, OFERTAS Y ASPECTOS SOCIALES DE LA EDUCACIÓN SUPERIOR VIRTUAL}

a categoría temática de trabajos que da nombre a la primera sección es la de "Políticas, ofertas y aspectos sociales de la educación superior virtual". Esta categoría incluye dos capítulos sobre las condiciones generales de la oferta, la demanda, el potencial público y la concentración de la cobertura y los logros de los estudiantes y los desafíos que plantea la implementación de la educación virtual.

El capítulo 1 versa sobre el e-learning y su impacto y penetración en las instituciones de educación superior en Colombia. Los autores indagan en diferentes bases de datos oficiales existencia, localización, niveles y población que acogen los programas virtuales en educación superior. Este estudio plantea la concentración de oportunidades, en contraste con un aumento de la oferta fuerte de programas casi siempre desde instituciones educativas privadas, sin políticas claras de continuidad, sostenibilidad y calidad.

El capítulo 2 muestra la relación entre la buscada ruptura de barreras de acceso a la educación superior mediante la educación virtual y las tendencias de concentración geográfica de oportunidades educativas en las metrópolis colombianas, exponiendo, a través de un estudio fundamentado en la educación basada en la evidencia, que este es un gran desafío para la implementación de la educación superior virtual en Colombia y la investigación sobre ella en periodos de su surgimiento y desarrollo inicial.

Por último, el capítulo 3 reitera la idea de la educación virtual como oportunidad de democratización del conocimiento que se acompaña de un desafío a su implementación en los niveles tecnológico, organizacional, financiero y cultural. A través de la indagación de tales desafíos en su propia institución (mediante análisis descriptivos, de contenido y de fuentes), este trabajo muestra hallazgos en torno a la necesaria articulación entre funciones, actores y procesos que permitan el buen desarrollo de la modalidad y el cumplimiento de sus propósitos. 


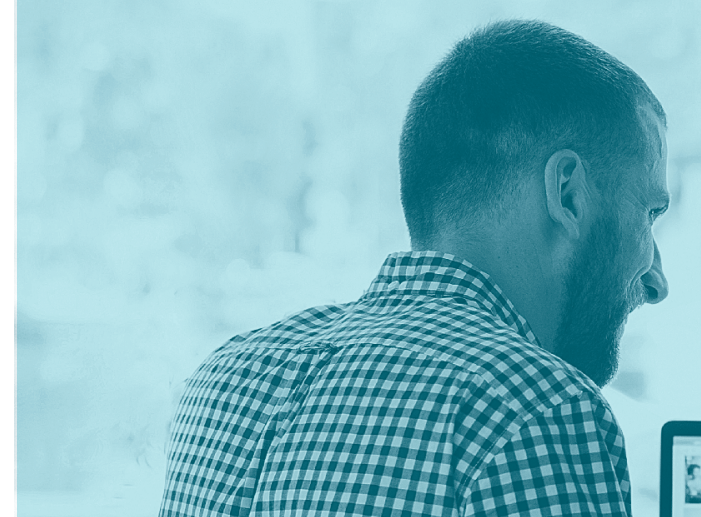




\title{
1. Panorama de la educación virtual en instituciones de educación superior en Colombia ${ }^{1}$
}

\author{
Diana Marcela Cardona-Román \\ Jenny Marcela SÁnchez-TorRes \\ CAMilo Andrés Acosta-Márouez
}

\section{Introducción}

A lo largo de las últimas décadas, el Ministerio de Educación Nacional (Mineducación) de Colombia ha centrado sus esfuerzos en el mejoramiento de las condiciones de calidad de la oferta educativa, especialmente la orientada a la educación superior. En este sentido, ha buscado continuamente ajustarse a los nuevos paradigmas globales, de modo que la educación en Colombia se acerque a los propósitos y las necesidades de la sociedad, el país y el mundo. El impacto de los medios de comunicación y las tecnologías de la información y la comunicación (TIC), es decir, la globalización y el cambio tecnológico, ha fortalecido la emergente economía global "basada en la tecnología e impulsada por la información y el conocimiento” (Aktaruzzaman, Shamim y Clement, 2011), donde la educación tiene un papel fundamental.

Esta economía global tiene implicaciones para las instituciones educativas, habida cuenta de que las "reta" a transformarse estructuralmente para afrontar estos cambios (Cabero, 2010; Schneckenberg, 2004). Además, a medida que el acceso a la información continúa creciendo de manera exponencial, las instituciones de educación superior (IES) no pueden seguir siendo solo espacios para la transmisión de un determinado conjunto de

1.. Agradecemos a la Corporación Red Nacional de Tecnologías Avanzadas (Renata) por permitir la utilización de datos obtenidos y relacionados con el Contrato n. ${ }^{\circ} 738$ de 2012 con el Mineducación para el fortalecimiento del e-learning, al Mineducación por proveer documentos de trabajo, información de los resultados de convocatorias de años anteriores relacionadas apoyo a la formación virtual y por ser el enlace entre los autores y las IES seleccionadas para la muestra y a Colciencias por el apoyo con la estudiante de doctorado a través de la convocatoria de doctorados nacionales No. 567 de 2012.

Diana Marcela Cardona Román. Ingeniera de Sistemas por la Universidad de Los Llanos, magíster en Ingeniería de Sistemas y Computación por la Universidad Nacional de Colombia y doctora en Ingeniería Industria y Organizaciones por la misma universidad. e-mail: dmcardonar@unal.edu.co

Jenny Marcela Sánchez Torres. Ingeniera de sistemas por la Universidad Nacional de Colombia, magíster en Análisis y Gestión de Ciencia y Tecnología por la Universidad Carlos III de Madrid, magíster en Ingeniería de Sistemas por la Universidad Nacional de Colombia y doctora en Economía y Gestión de la Innovación y Política Tecnológica por la Universidad Autónoma de Madrid. Profesora titular del Departamento de Ingeniería de Sistemas e Industrial de la Universidad Nacional de Colombia.e-mail: jmsanchezt@unal.edu.co

Camilo Andrés Acosta Márquez. Magíster en Mecatrónica y en Ingeniería Eléctrica, doctor en Robótica. Gerente de proyectos Grupo Método. e-mail: camilo.acosta.marquez@outlook.com 
información del maestro al estudiante durante un periodo fijo. Más bien, estas deben promover la adquisición de conocimientos y habilidades que hacen posible el aprendizaje continuo durante toda la vida (Thornburg, 2000, citado en Aktaruzzaman, Shamim y Clement, 2011).

La utilización de las tecnologías multimedia y de internet para mejorar la calidad del aprendizaje y facilitar el acceso a recursos y servicios y los intercambios y la colaboración a distancia es la definición dada al sintagma e-learning por la Comisión Europea en 2001 (Cardona-Román y Sánchez-Torres, 2011). Por su parte, el Mineducación (2010a) concibe el e-learning como educación virtual, que es el

desarrollo de un proceso educativo en un lugar distinto al salón de clases: en el ciberespacio; en una temporalidad que puede ser síncrona o asíncrona y sin la necesidad de que los cuerpos de maestros y estudiantes estén presentes. Para ello se usan las redes telemáticas que se constituyen en su entorno principal. (p. 33)

Así es como el Mineducación pretende mantener el país en la vanguardia de innovación educativa con uso de la tecnología, por lo cual se esfuerza en realizar acciones que promuevan los avances en el sector y procura se beneficien las comunidades educativas del país.

Así, el Plan Nacional de Desarrollo 2010-2014, en su política de crecimiento sostenible y competitividad, propuso el mejoramiento de la calidad de la educación y el desarrollo de competencias, al justificar que la mayoría de los países desarrollados con exportaciones de alto nivel tecnológico dedican un mayor número de profesionales a investigación y desarrollo, de ahí la importancia de la formación de calidad y pertinencia con espacios de articulación y diálogo permanente entre el sector educativo y el sector productivo (DNP, 2011).

Además, en el Plan Nacional de Desarrollo 2014-2018, uno de los tres pilares fundamentales es la educación, vista como un instrumento de crecimiento económico a largo plazo y concebida con la visión de cerrar brechas de acceso y calidad al sistema educativo, para lograr la igualdad de oportunidades y acercar el país a los estándares internacionales (DNP, 2014).

Por ello, el Mineducación encuentra en la educación virtual una alternativa de formación valiosa para muchos colombianos, dado que permitiría alcanzar los objetivos planteados en los planes de desarrollo, aprovechando para ello las ventajas propias que son inherentes a la educación virtual, que permitiría ampliar la cobertura e inclusión de personas que, por motivos culturales, sociales o económicos, no se adaptan a los sistemas convencionales de educación, posibilitando una educación para todos, con capacitación masiva en competencias básicas digitales y ejecución de programas académicos, con por lo menos 80 \% de cursos virtuales (Mineducación, 2010a). No obstante, como se verá 
Comunicación, redes, aprendizaje y desarrollo institucional y social

en el desarrollo de este estudio, el panorama de la educación virtual en Colombia deja ver algunas insolvencias frente al cumplimiento de los objetivos, debido a que la implementación de estas tecnologías trae consigo consecuencias que requieren una cuidadosa consideración, además de verificar la mejora potencial en el proceso de aprendizaje luego de su aplicación (Neill, Singh y Donoghue, 2004; Aktaruzzaman, Shamim y Clement, 2011).

El crecimiento de la sociedad de la información impulsa la actualización constante de panoramas en el ámbito educativo, por tanto, el alcance de este estudio en particular es realizar el análisis de la situación actual de la educación virtual en Colombia y de la oferta de programas virtuales implementados con subvención del Estado a partir de una muestra de IES.

Este estudio, además de contener el panorama de la educación virtual en Colombia, presenta la metodología empleada para la construcción y los resultados de la investigación. En la metodología, se explica el proceso de recolección de los datos a partir de información proporcionada por el Mineducación y las IES. En los resultados, se realiza una exploración del contexto y las políticas que apoyan la educación virtual en Colombia y la aplicación de una encuesta a una muestra de IES que recibieron apoyo financiero y de capacitación por parte del Estado, particularmente del Mineducación, para la oferta de programas virtuales. Por último, se exponen las conclusiones derivadas de la investigación.

\section{Metodología}

Para el desarrollo de este estudio, se utilizó un enfoque de análisis secuencial exploratorio y se ejecutaron tres etapas que se describen a continuación:

- Revisión del contexto colombiano en la educación virtual: esta etapa exploratoria abarcó la búsqueda de las iniciativas adelantadas en Colombia en la educación virtual. Para ello, se revisaron los avances del Mineducación en los planes sectoriales, el Sistema Nacional de Información de Educación Superior (SNIES), el Observatorio Laboral para la Educación y documentos de trabajo interno que contenían información relevante del avance de la educación virtual en Colombia.

- Recolección de datos de programas virtuales en Colombia: en esta etapa, se recopiló la información específica de oferta de programas virtuales en Colombia, que incluye admisiones, matrículas, graduados, área de conocimiento, localización geográfica, nivel académico y nivel de formación.

- Recolección general de datos de los programas virtuales: para realizar esta fase, se recurrió a la búsqueda general de información ofrecida por el SNIES, en particular, datos de los programas virtuales registrados en Colombia. 
- Muestra de datos de programas apoyados por el Mineducación: a partir de un listado de 54 IES y 125 programas que fueron apoyados por el Mineducación en diferentes convocatorias de transformación y creación de programas virtuales en el periodo de 2008 a 2012, se realizó un análisis de aquellos que contaban con registro calificado y se obtuvo 29 IES con 62 programas técnicos y tecnológicos apoyados financieramente (programas que se relacionan con los apoyados en las convocatorias de 2008 a 2010, convocatorias que solo iban dirigidas a esta población). A partir de ahí, se obtuvo una muestra de $25 \%$ de programas e instituciones que correspondió a 10 IES con 17 programas. Los programas apoyados en 2011 presentaron documentos para registro calificado en 2012, por lo cual en el momento de la realización de esta recolección de datos aún estaban a la espera de la respuesta de obtención de dicho registro para poder ofrecer el programa; y los programas apoyados en 2012 presentaron sus registros calificados a mediados de 2013. Es pertinente indicar que desde la convocatoria de 2011 se inició un proceso de apoyo a programas universitarios, especializaciones y maestrías, asi que la muestra de IES y programas fue intencional y aportó información sobre la formación virtual apoyada en Colombia. Además, se identificaron variables e indicadores y se elaboró un instrumento tipo encuesta para la recolección de la información sobre la muestra de las IES. La encuesta fue validada por tres funcionarios expertos en educación del Mineducación, cuyo fin fue ampliar la información relacionada con la cobertura, la pertinencia, la calidad, el material de apoyo y la docencia en los programas virtuales muestreados. Esta fase contó con el apoyo de la Corporación Red Nacional de Tecnologías Avanzadas (Renata) y con el Mineducación a través del Contrato n. ${ }^{\circ} 738$ de 2012, datos recolectados en noviembre y diciembre de 2012.

- Análisis de los resultados: finalmente, para realizar los análisis de los resultados encontrados, se consolidó la información, se utilizó el análisis cuantitativo y descriptivo de los datos recopilados y se realizaron gráficos utilizando Microsoft Excel ${ }^{\circledR}$ como software de apoyo para su elaboración. La primera parte del análisis corresponde a la información de la recolección general y la segunda a los resultados de la encuesta hecha a una muestra de IES subvencionadas por el Estado para el fortalecimiento de las capacidades para la oferta de programas virtuales.

\section{Resultados}

Esta sección muestra los resultados obtenidos siguiendo la metodología propuesta. Inicia con la revisión del contexto y las políticas de la educación virtual en Colombia y luego presenta la situación general de esta. Para ello, se define la estructura de recolección de infor- 
Comunicación, redes, aprendizaje y desarrollo institucional y social

mación registrada de forma oficial en los sistemas de información del Mineducación y se recoge información de manera directa a partir de una muestra de IES que recibieron apoyo financiero de este.

\section{Revisión del contexto colombiano en la educación virtual}

Este apartado despliega, sin ser exhaustivo, las acciones más relevantes del fortalecimiento de la educación virtual en Colombia desde los planes sectoriales educativos, las metas gubernamentales que apalancaron este proceso formativo, la normativa legislativa hasta la relación con los avances de las instituciones educativas en la implementación de las TIC en la educación superior reflejados en la cantidad de programas de pregrado y posgrado registrados ante el ente nacional.

Durante los últimos años las acciones desarrolladas por el Mineducación han permitido alcanzar logros importantes en la oferta de programas virtuales en cuanto cobertura, infraestructura, modernización del sector y evaluación de la calidad, según lo indican en la evaluación que realizan de sus planes sectoriales. Inicialmente, debido a la política educativa denominada Revolución Educativa plasmada en el Plan Sectorial de Educación 2002-2006 y continuada en el Plan Sectorial de Educación 2006-2010, el cual propuso transformar el sistema educativo colombiano en magnitud y pertinencia, impulsando estrategias que apuntaron a expandir la cobertura con criterios de equidad, mejoramiento de la calidad y aumento de la eficiencia y productividad del sector, propendiendo a la ampliación del acceso a la educación superior con racionalización de recursos, acceso a contenidos de calidad, fortalecimiento de la capacidad de uso y apropiación, acceso a infraestructura tecnológica y la modernización de la gestión de las universidades públicas, con el ánimo de favorecer la adopción de nuevas metodologías en los programas presenciales, a distancia y virtuales (Mineducación, 2003).

Debido a los avances y logros obtenidos, precisamente, la meta del Mineducación para el cuatrienio 2006-2010 fue la creación de cien programas académicos con más de 80 \% de virtualidad. No obstante, a la fecha de la publicación del plan había 38 programas virtuales y al finalizar el periodo 164, lo cual dio apertura a las nuevas actividades dentro de tres ejes de operación: 1) desarrollo profesional del recurso humano, 2) soporte y asistencia técnica y 3) evaluación y monitoreo (Ley 1188/2008).

La política continuó fortaleciendo el e-learning en el plan de desarrollo sectorial educativo 2010-2014 que proyectó que en Colombia se educara con pertinencia e innovación, previendo estrategias que fomentaron el uso de las TIC, como acceso a tecnología, formación de la comunidad educativa, gestión de contenidos y consolidación de un programa 
nacional de innovación educativa, con el propósito de integrar las TIC como parte del proceso pedagógico de los docentes, los estudiantes y, en general, de la comunidad educativa del país (Mineducación, 2011).

El Programa Nacional de Innovación Educativa se enmarcó dentro de la estrategia para la pertinencia "uso y apropiación de medios y nuevas tecnologías", propuesta en el Plan Nacional de Desarrollo 2010-2014 (DNP, 2011) como una estructura con cuatro ejes misionales y dos ejes transversales. Los ejes misionales estuvieron compuestos por 1) uso y apropiación de medios y TIC, 2) desarrollo profesional del recurso humano, 3) gestión de contenidos y 4) gestión de infraestructura tecnológica. Mientras que los ejes transversales buscaron consolidar 1) red nacional de acompañamiento y asistencia técnica y 2) monitoreo y evaluación.

Dentro de las estrategias del plan sectorial educativo está la educación virtual. Estrategia que proyecta la educación virtual como aquella que permite a las IES llegar a todos los habitantes del territorio nacional, independienteme del lugar en el que se encuentren, superando los límites de distancia y propiciando ambientes de aprendizaje flexibles, con el fin de tener otra alternativa para cierre de brechas (Mineducación, 2010a, 2011). Para ello, el plan propuso como meta del cuatrienio 2010-2014 brindar asistencia técnica y acompañamiento a las IES en la creación y transformación de 300 programas virtuales (Mineducación, 2011), teniendo en cuenta calidad, cobertura, eficiencia, pertinencia y las TIC como eje transversal del currículo. Al revisar los programas asesorados a través de los servicios de asistencia técnica y acompañamiento, se tuvieron 182 programas durante el cuatrienio. Esto pudo significar el no cumplimiento de la meta, no obstante, ella se cumplió a cabalidad por las iniciativas propias de las IES de crear programas virtuales.

En consonancia con la revisión de la normativa, Visión: educación propuesta para discusión y el Plan Nacional Decenal de Educación 2006-2016 propusieron el mejoramiento de la calidad de la educación y el desarrollo de competencias. Para lograrlo, plantean avanzar en 1) la construcción de una infraestructura de calidad y desarrollo de contenidos, 2) definición de estándares y formación de estudiantes y docentes para uso adecuado y apropiación de las nuevas tecnologías en la educación y 3) consolidación de comunidades y redes educativas virtuales que aprovechen las ventajas que ofrecen las TIC y generen nuevos conocimientos a partir de su explotación. Aspectos que están alineados con algunas estrategias² que fomentan el uso de las tecnologías mencionadas.

Sin embargo, pese a que en el Plan Nacional de Desarrollo 2014-2018 se plantea la educación como uno de sus tres pilares fundamentales, se carece de líneas de acción específicas

2 Con las estrategias del Plan Sectorial 2010-2014, como 1) la formación de la comunidad educativa y 2) la gestión de contenidos. 
para llevar a cabo el cierre de la brecha de acceso a la educación superior (Ley 1753/2015). En ese sentido, solo propone ampliar la cobertura de alta calidad, que pasó de 14.2 a 20 \% al finalizar 2018 (DNP, 2014; Fedesarrollo, 2014), y no se contempla el fortalecimiento de la educación virtual, lo cual deja un vacío frente a la continuidad de las acciones de fortalecimiento de las capacidades institucionales para la oferta de programas académicos virtuales.

Por otra parte, en el aspecto normativo, se incorpora la educación virtual en la Ley 1188/2008, reglamentada, inicialmente, en el Decreto 1295/2010, dos años después de la ley y ocho años más tarde desde que apareció por primera vez el concepto en un plan sectorial de educación en Colombia. Posteriormente, fue recopilada en la parte quinta de la reglamentación de la educación superior, del Decreto 1075/2015, decreto reglamentario único del sector educación. El decreto reglamentario precisa las condiciones de calidad exigidas a los programas virtuales para obtener su registro calificado. No obstante, y de acuerdo con la experiencia que han tenido las diferentes IES al crear programas académicos virtuales, estas dan cuenta de que la reglamentación deja de lado la condición misma de los programas virtuales y la valoración para la obtención de registro calificado resulta un tema sesgado a la experiencia o afinidad de los evaluadores con este tipo de formación.

Finalmente, la incursión tecnológica en la educación superior, según la obra Revolución Educativa 2002-2010: acciones y lecciones, que recoge las memorias para educación virtual (e-learning) precisa:

En 2002, la oferta de programas virtuales en el país era de seis programas académicos pertenecientes a cuatro instituciones de educación superior, de los cuales cuatro eran de pregrado y dos de posgrado. Como parte de la estrategia de desconcentración de la oferta que se inició en 2003, para garantizar mayor acceso de la educación superior, se llegó a la conclusión de que la educación virtual permitía ampliar cobertura con menor costo, al no requerir grandes infraestructuras físicas en zonas apartadas del país. Es así como, en 2003, comenzó el programa de incorporación de TIC a la educación superior que buscaba generar la capacidad instalada en infraestructura en las instituciones, la creación de contenidos, la formación docente y la definición de políticas para avanzar hacia el desarrollo de programas virtuales. Al finalizar 2006, la oferta de 13 instituciones de educación superior subió a 18 programas (12 de pregrado, 4 especializaciones y 2 maestrías), pero con poca cobertura de estudiantes.

Ante los lentos avances en cobertura, en 2008 se convocó a instituciones de educación superior para que acompañaran la transformación de 18 programas 
a distancia técnicos y tecnológicos en programas virtuales, buscando ampliar la oferta de programas de los CERES y en los municipios donde no existía presencia de instituciones de educación superior. (Mineducación, 2010b, p. 119 y 120)

En 2009, el Mineducación apoyó un grupo de 17 instituciones para la creación de 28 programas de educación superior y así, para ese año, se tenía 36 IES que ofrecían más de 150 programas académicos con más de 80 \% de virtualidad en los niveles técnico profesional, tecnológico, profesional universitario, de especialización y maestría en diferentes áreas del conocimiento (Mineducación, 2010b, p. 120).

En 2010, nuevamente, el Mineducación convocó a las instituciones con el fin de crear programas virtuales en maestría, especialización y pregrado, donde se apoyó a nueve instituciones con 18 programas. En 2011, se amplió la oferta de asesoramiento a 27 programas de 13 instituciones. En 2012, el Mineducación cambió de operador de la estrategia y el nuevo operador asesoró la creación inicialmente de 47 programas de 18 instituciones, pero, al finalizar el asesoramiento, fueron 60 los programas virtuales que recibieron capacitación en su formulación. En 2013, el proyecto asesoró a 21 IES, las cuales crearon 40 programas virtuales. En 2014, el proyecto se transformó y fue dirigido solo a las IES y no a los programas; mediante este proyecto, el Mineducación asesoró a 37 IES en la creación de nuevos programas virtuales contextualizados con las necesidades locales. La consecuencia de dejar capacidad instalada a partir del trabajo de asistencia técnica generó en algunas IES la formulación de nuevos programas virtuales por iniciativa propia, los cuales fueron registrados ante el ente competente y así cumplió la meta que el Gobierno nacional tenía para el cuatrienio 2010-2014. Para 2015, el Mineducación no destinó recursos para esta estrategia de fortalecimiento de la educación virtual (DNP, 2014), sin embargo, sí recursos para consolidar un documento técnico para la educación virtual, documento base que proveyó lineamientos para la educación virtual en el ámbito colombiano, y que fue socializado en 2016 en el II Encuentro Nacional de e-Learning, evento organizado por el Mineducación. Teniendo en cuenta que la educación virtual no fue una prioridad para plan de gobierno de 2016-2018, esta línea de formación no tuvo recursos para seguir consolidándose.

En suma, la formulación de políticas, metas e indicadores que apoyen el fortalecimiento de la educación con el uso de las TIC tiene una relación directa con los avances de las instituciones educativas en la oferta académica de pregrado y posgrado, reflejados en el aumento de los programas virtuales registrados ante el ente nacional y visualizado en el SNIES. Lo anterior es confirmado con el Observatorio de la Universidad Colombiana, ${ }^{3}$ pues explica que

3 Portal web consultado el 15 de diciembre de 2012 donde se presentan varios indicadores relacionados con la educación superior. Se consulta así la distribución de los programas de educación superior según la metodología en la que se aprende (https://goo.gl/59kAGf). 
en 2010 hubo 199 programas correspondientes a $1.1 \%$ de la oferta total de programas de Colombia para ese año; en 2011, se identificaron 266 programas activos de metodología distancia virtual equivalentes a $2.46 \%$ de la oferta total de los programas; para 2012, el total de programas activos de la metodología distancia virtual fue de 266 programas equivalentes a $2.57 \%$ de la oferta total, aunque para el mismo año en el SNIES se registraron 273 programas virtuales (compuesto por 78 programas de posgrado y 195 de pregrado). Para 2013, el mismo observatorio reportó 350 programas a distancia virtual que equivalen a $3.6 \%$ de la oferta total académica en Colombia, con un incremento de casi $1 \%$ respecto del anterior. Para 2014, las estadísticas fueron consolidadas en 517 programas activos de distancia virtual equivalentes a $4.17 \%$ de la oferta total. Este porcentaje de oferta año a año ha venido incrementándose, mientras que para los programas de distancia tradicional el porcentaje de programas académicos activos ha sufrido una sensible baja en los últimos años de tener $6.93 \%$ en 2012 a tener $4.34 \%$ en 2014 y $4.14 \%$ en 2016 . Tendencias que se han mantenido también en 2015 y 2016, pues, como reportó el Observatorio, para 2015, se consolidaron 602 programas de distancia virtual activos, esto es, $4.61 \%$ de la oferta total, y para 2016 la oferta fue de 666 programas activos de distancia virtual, correspondientes a $4.97 \%$ de la oferta total. El incremento porcentual de la oferta de programas de modalidad distancia virtual en Colombia entre 2010 a 2016 fue de 3.87 \%. Así las cosas, los esfuerzos realizados por el Mineducación en las asesorías técnicas durante las convocatorias de los años anteriores (2010-2014) se visualizan en estos resultados con el incremento en la oferta de programas virtuales.

El contexto actual permite reconocer que en Colombia la formación virtual es relativamente nueva (primera década del siglo XXI) (Cardona-Román y Sánchez-Torres, 2011) al compararse con la educación a distancia (década de 1960) (Arboleda y Rama, 2013).) y con la educación presencial tradicional (finales del siglo XVI y transformadas entre los siglos XIX XX) (Misas, 2004; Herrera, 2017), considerando, además, los adelantos desde la planeación política, a partir de varias estrategias que logran extender el uso de las TIC como herramientas de apoyo en el proceso pedagógico. No obstante, aún existe rezago frente al desarrollo de este tipo de formación en comparación con otros países, y esto puede deberse a que se cumple con la meta de gobierno de turno, que el cuatrienio anterior fue la creación de programas y, además, se carece de políticas de seguimiento que garanticen la calidad y la sostenibilidad; profundizando un poco más en una causa, es posible que la falla sea desde las propias estructuras organizacionales de las instituciones que ofertan este tipo de programas, porque no se ajustan a los nuevos desafíos que implica la incorporación de innovaciones educativas como e-learning y continúan con la misma estructura organizacional rígida que soporta la formación presencial tradicional. 


\section{Recolección de datos de programas virtuales en Colombia}

A continuación, se presentan los resultados que describen los programas virtuales en Colombia.

\section{Recolección general de datos de programas virtuales}

Se definió la estructura de información ofrecida por SNIES así:

- Nombre de la institución

- Carácter de la IES

- Sector de la IES

- Nombre del programa

- Área del programa

- Núcleo básico común

- Departamento y municipio de oferta del programa

- Metodología

- Estado

- Nivel académico

- Nivel de formación

- Admitidos

- Matriculados

- Graduados

Se realizó una búsqueda en dos momentos; la búsqueda del primer momento corresponde a 2012, ${ }^{4}$ que se usará para tener una línea base, mientras que la búsqueda del segundo momento corresponde a $2015^{5}$ como datos comparativos. Para la búsqueda del primer momento, se encontraron en la metodología de educación a distancia (virtual y tradicional) 1250 registros de programas académicos; si bien solo 851 programas (a distancia virtual y tradicional) se hallaron activos (68\%), se identificaron 273 registros de programas activos para educación virtual. Para la búsqueda del segundo momento, se encontraron 1573 registros de programas académicos (distancia tradicional y virtual), de los cuales 1070 están activos (68\%) y de ellos 532 son programas virtuales.

4 La búsqueda se realizó en el SNIES en noviembre y diciembre de 2012, los datos de admitidos, matrícula y graduados corresponde a lo reportado por las IES para 2011

5 La búsqueda se realizó en el SNIES en julio de 2015. 
Comunicación, redes, aprendizaje y desarrollo institucional y social

\section{Muestra de datos de programas apoyados por el Mineducación}

A partir de diferentes apoyos que el Mineducación ha realizado para la generación de capacidades en la creación y transformación de programas virtuales en las IES colombianas, se seleccionaron de manera intencional 10 IES con 17 programas, que corresponden a $25 \%$ del total de IES apoyadas por el Mineducación del periodo 2008-2010. Estas instituciones fueron seleccionadas a partir de diferentes características como: 1) metodología de oferta a distancia tradicional y virtual; 2) cantidad de matrícula en I 2011-2 (alta, baja, nula), donde alta corresponde a matrícula superior a 90 estudiantes en el semestre, matrícula baja a matrícula menor de 50 estudiantes y matrícula nula a programas con matrícula cero o sin datos; 3) diverso nivel de formación; 4) participación en varias convocatorias; y 5) que fueran de diferentes ciudades. Lo anterior permite tener una muestra significativa de las instituciones que engloban el territorio nacional y así poder obtener un escenario más completo y con información proveniente de las IES.

Una vez seleccionadas las instituciones y los programas, se procedió a revisar el sistema de información del Observatorio Laboral para la Educación ${ }^{6}$ del Mineducación, considerado una herramienta que promueve la innovación y el mejoramiento de la calidad y la pertinencia de los programas de educación superior, puesto que los resultados son producto del cruce de información suministrada por las IES al SNIES, y las bases de datos de seguridad social del Ministerio de Salud y Protección Social y del Ministerio de Hacienda y Crédito Público, proceso mediante el cual se calculan dos indicadores: 1) el porcentaje de graduados que hace parte del sector formal de la economía y 2) su salario promedio. Sin embargo, solo se encontró información de cuatro programas ${ }^{7}$, es decir, 23 \% de los programas seleccionados en la muestra; es evidente, entonces, la deficiencia existente en la actualización de los sistemas de información estales.

\section{Análisis de los resultados}

Este apartado contiene el detalle de los resultados globales en educación virtual en Colombia teniendo en cuenta los datos reportados en el SNIES para los dos momentos de medición, 2012 y 2015. Además, contiene los resultados obtenidos del análisis de la recolección de información realizada a las IES.

6 El sitio web se encuentra disponible en www.graduadoscolombia.edu.co.

7 Datos consultados en 01/12/2012. 


\section{Resultados generales}

A continuación, se presenta el análisis de datos del SNIES. El análisis de resultados del primer momento se realizó en el periodo comprendido entre noviembre y diciembre de 2012. Es interesante notar que las IES que incursionan en el campo del e-learning corresponden a las ubicadas en el sector privado, con $86 \%$ de participación en la oferta virtual con 236 programas registrados en el SNIES, en contraste con $14 \%$ de IES oficiales que son algo más "temerosas" en la oferta de programas virtuales, equivalentes a 37 programas registrados.

Para el segundo momento de exploración de datos, se realizó una búsqueda al 20 de julio de 2015, en la cual se encontraron 532 programas, de los cuales $83 \%$ (441) son programas ofertados por IES del sector privado, en contraste con 17 \% (91) de programas ofertados por IES del sector oficial, siguiendo la tendencia en la cual la oferta de programa virtuales es suplida por IES privadas.

Para 2012, las IES que ofertaban programas virtuales en Colombia se caracterizaron por universidades que ofrecían 153 programas equivalente a $56 \%$, instituciones universitarias o escuelas tecnológicas que ofrecían 97 programas que corresponden a $36 \%$ e instituciones tecnológicas con $8 \%$ de oferta de programas virtuales, es decir, 23 programas.

Para 2015, el panorama en cuanto al carácter de las IES que ofertan programas virtuales no tiene cambios significativos, aunque el aumento en el número de programas es lo que marca la diferencia. En 2015, las universidades ofertan 48 \% (257) de los programas virtuales, las instituciones universitarias o escuelas tecnológicas $38 \%$ (202) de los programas, las instituciones tecnológicas $11 \%$ (60) de los programas y las instituciones técnicas profesionales solo 13 programas virtuales. El análisis comparativo se observa en la figura 1.1.

Para 2012, se encontró que el Mineducación apoyó a un grupo de instituciones con el fin de madurar la oferta de programas virtuales en el nivel académico de pregrado, concentrados en $71 \%$ de programas técnicos, tecnológicos y universitarios, es decir, 195 programas, mientras que $29 \%$ restante corresponde a programas de posgrado (especializaciones y maestrías), equivalentes a 78 programas activos con registro calificado para dicho año.

La distribución porcentual de oferta de los programas virtuales para 2012 según el nivel de formación es mayor en los programas técnicos y tecnológicos, con 26 \% y 25 \% de la oferta total de programas virtuales, respectivamente, que corresponden a 72 programas para formación técnica profesional y 68 para formación tecnológica. Esta concentración se debió al apalancamiento que diera el Mineducación a través de convocatorias en 2008 
Figura 1.1. Programas virtuales por carácter de las IES.

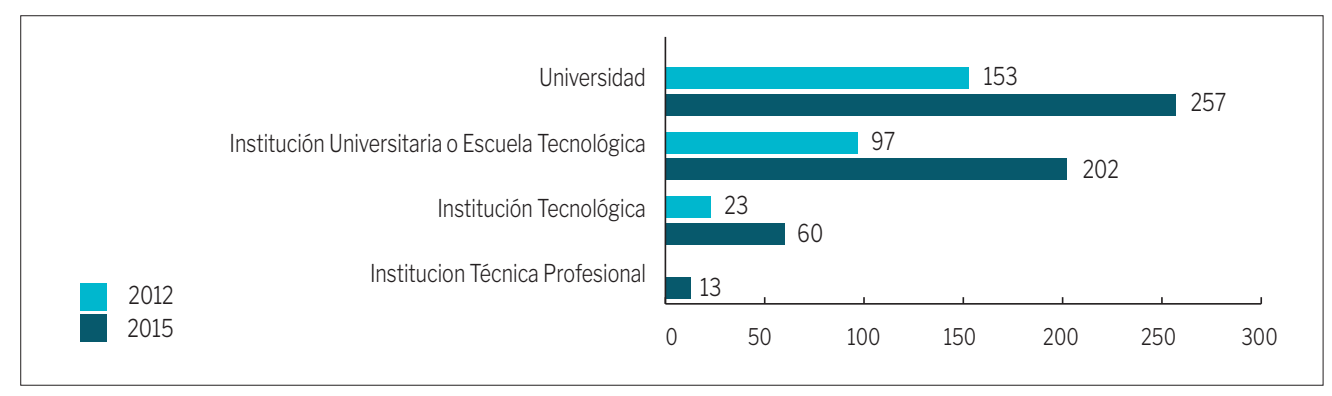

Fuente: Elaboración propia según datos del SNIES corte 1/12/2012 y 20/07/2015.

Figura 1.2. Programas virtuales por nivel educativo.

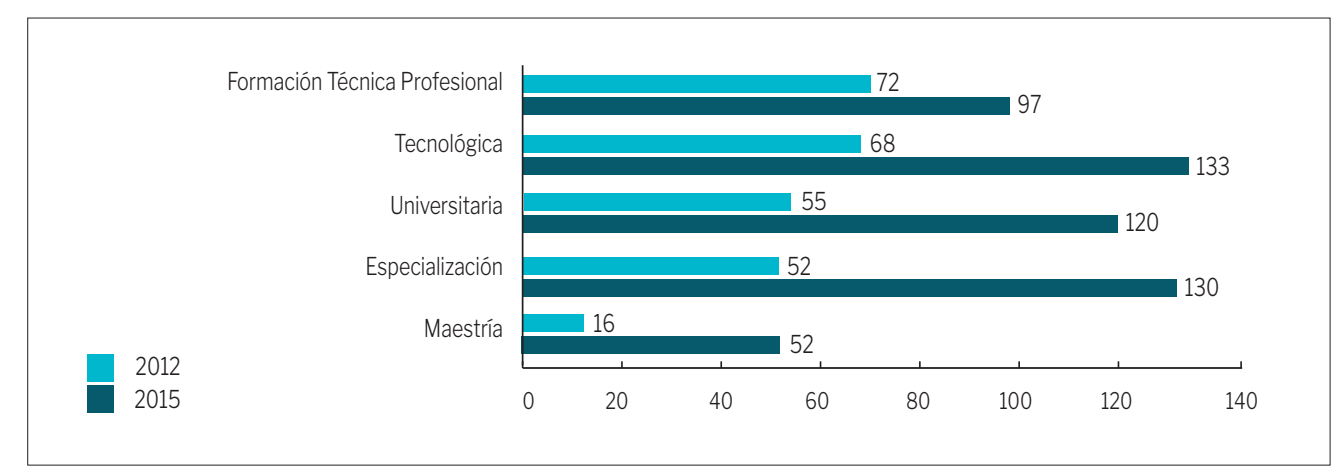

Fuente: Elaboración propia según datos del SNIES corte 1/12/2012 y 20/07/2015.

y 2009, cuyo apoyo se centraba de manera exclusiva en estos niveles de formación, sin embargo, como se enunció, algunas instituciones por iniciativas propias emprendieron el camino de la oferta de programas virtuales de pregrado y posgrado, algunos de ellos favorecidos en las siguientes convocatorias del Mineducación como las de 2010, 2011 y 2012. Continuando el análisis, la formación virtual en especialización para 2012 ocupó 23 \% de la distribución total, es decir, 62 programas, seguido de la formación en pregrado, con $20 \%$ (55 programas), y finalmente los programas de maestría tuvieron $6 \%$ de la oferta que correspondió a 16 programas registrados en el SNIES.

Para 2015, se identificaron 182 programas de posgrado, equivalentes a $34 \%$ de la oferta de programas virtuales, en contraste con un mayor número de programas de pregrado con 350, que se estiman en 66 \% de la oferta. De acuerdo con el nivel de formación ofrecido por cada programa, se encontró que la formación técnica profesional cuenta con 97 programas, la formación tecnológica con 133 programas, la formación universitaria cuenta con 120 programas, la formación especializada con 130 programas y la formación de maestría con 
52 programas. La figura 1.2 muestra el análisis comparativo de los programas por nivel de formación y por momento de recolección de datos.

Respecto de las condiciones de calidad que ostentan los programas virtuales activos en Colombia para 2012, se encontró que 91 \% contó con el reconocimiento del registro calificado, correspondiente a 250 programas, solo 1 \% estaba acreditado de alta calidad, es decir, dos programas, habida cuenta que son programas relativamente nuevos, y $8 \%$ no contó con ningún reconocimiento del Mineducación o con una condición particular; estos son 21 programas que no lograron renovar su registro calificado en el tiempo disponible paralo y quedan en estado no aplicó.

Para 2015, se observa un aumento en las condiciones de calidad que ostentan los programas virtuales activos en Colombia, que da cuenta deque $98 \%$ de los programas ofertados tiene registro calificado, correspondiente a 520 programas, 3 programas tienen registro de alta calidad y 9 programas, todos ellos registrados en el 2009, no tienen ningún reconocimiento del Mineducación o no aplicaron para la renovación de este.

La oferta de los programas virtuales distribuidos por áreas de conocimiento en 2012 presentó una concentración de 48 \% en las áeras de de economía, administración, contaduría y afines, es decir, 131 programas. El 22 \% correspondió a las áreas de ingeniería, arquitectura, urbanismo y afines, esto es, 61 programas. El $10 \%$, es decir, 27 programas, se adscribió al área de ciencias de la educación, 9 \% de los programas fueron del área de las ciencias sociales y humanas, que correspondió a 25 programas. El área agronomía, veterinaria y afines tuvo $6 \%$ de los programas que equivale a 16 programas. El área de matemáticas y ciencias naturales tuvo adscritos 8 programas correspondientes a $3 \%$; el porcentaje restante de la distribución por áreas de conocimiento albergaron menos de $3 \%$ de los programas virtuales activos en Colombia, estas áreas fueron bellas artes, con $2 \%$ equivalente a cuatro programas y ciencias de la salud con un programa.

Para 2015, la distribución de los programas por áreas de conocimiento tuvo la misma composición; el cambio radicó en la cantidad de programas creados para área de conocimiento de bellas artes, que pasó de tener 4 programas a 10, aunque la distribución porcentual se mantuvo. En la tabla 1.1, se observa el comparativo de 2012 y 2015.

Con relación a la cobertura académica por departamentos en Colombia, se observó, para 2012, que la distribución de programas virtuales ofrecidos, según la división política de Colombia, muestra la concentración de programas de ciudades representativas, como Bogotá, Medellín, Cali y Bucaramanga, dado que son en estas donde funcionan las sedes principales de la mayoría de las IES. En Bogotá, la oferta de programas virtuales fue de 97 
Tabla 1.1. Programas virtuales ofertados por área de conocimiento

\begin{tabular}{|c|c|c|c|c|}
\hline \multirow{2}{*}{$\begin{array}{c}\text { Área de conocimiento } \\
\text { de los programas virtuales }\end{array}$} & \multicolumn{2}{|c|}{2012} & \multicolumn{2}{|c|}{2015} \\
\hline & $\begin{array}{c}\text { \# de } \\
\text { programas }\end{array}$ & $\begin{array}{l}\text { Distribución } \\
\text { porcentual }\end{array}$ & $\begin{array}{c}\text { \# de } \\
\text { programas }\end{array}$ & $\begin{array}{l}\text { Distribución } \\
\text { porcentual }\end{array}$ \\
\hline $\begin{array}{l}\text { Economía, administración, } \\
\text { contaduría y afines }\end{array}$ & 131 & 48 & 289 & 54 \\
\hline $\begin{array}{l}\text { Ingeniería, arquitectura, urbanismo } \\
\text { y afines }\end{array}$ & 61 & 22 & 102 & 19 \\
\hline Ciencias de la educación & 27 & 10 & 58 & 10 \\
\hline Ciencias sociales y humanas & 25 & 9 & 45 & 8 \\
\hline Agronomía, veterinaria y afines & 16 & 6 & 16 & 6 \\
\hline Matemáticas y ciencias naturales & 8 & 3 & 8 & 1 \\
\hline Bellas artes & 4 & 2 & 10 & 2 \\
\hline Ciencias de la salud & 1 & 0 & 4 & 0 \\
\hline Total & 273 & 100 & 532 & 100 \\
\hline
\end{tabular}

Fuente: Elaboración propia según datos del SNIES corte 1/12/2012 y 20/07/2015.

que corresponde a $35 \%$ de la oferta total; no obstante, Antioquia se registró 23 \% con 64 programas, Santander $20 \%$ con 57 programas, Bolivar 4 \% con 12 programas, Valle del Cauca $2.5 \%$ con 7 programas; el resto de la oferta de programas virtuales corresponde a los departamentos de Atlántico, Tolima, Nariño, Norte de Santander, Caldas, Quindío, Boyacá, Cundinamarca, Chocó, Risaralda, con $2 \%$ o menos cada uno.

Para 2015, se registra un sensible aumento en la oferta de programas virtuales en Bogotá, de pasar de 97 programas a ofertarse 261 programas que equivalen a $67 \%$ de la oferta, un crecimiento de $32 \%$. Antioquia contó con 89 programas relacionados con $17 \%$, para Santander se registraron 72 programas, equivalentes a $13 \%$, el restante $3 \%$ corresponde a los departamentos de Atlántico, Valle del Cauca, Bolívar, Caldas, Sucre, Norte de Santander, Boyacá, Nariño, Cundinamarca, Tolima, Risaralda, Quindío, Cauca, Chocó y Magdalena.La figura 1.3 muestra el crecimiento comparativo para los departamentos que ofertan programas virtuales. 
Figura 1.3. Distribución de programas virtuales por departamento.

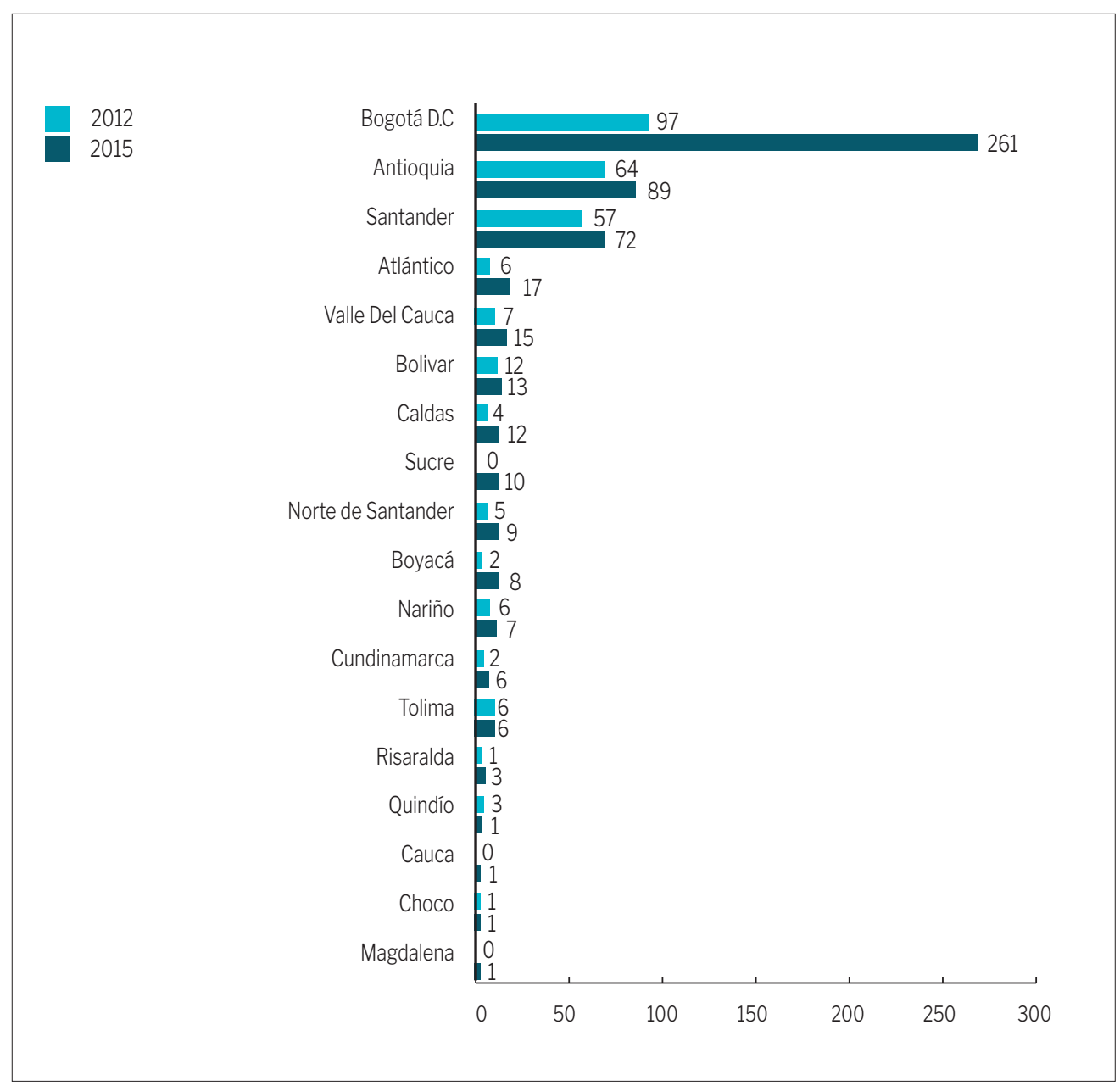

Fuente: Elaboración propia según datos del SNIES corte 1/12/2012 y 20/07/2015.

Al profundizar en el comportamiento histórico de la cobertura en la oferta de programas virtuales teniendo en cuenta el número de matrículas anuales, se muestra la figura 1.4, que contiene la relación de las matrículas y los graduados en la modalidad a distancia tanto tradicional como virtual, donde se evidencia un leve crecimiento de los matriculados en los programas virtuales y en sus graduados. Sin embargo, es evidente que este crecimiento se encuentra concentrado geográficamente en las principales ciudades, como se explicaba, por tanto, se pone en evidencia que los esfuerzos del Mineducación están aún lejos de tener una cobertura geográfica de estudiantes en esta modalidad. 
Figura 1.4. Relación anual de matrículas y graduados por metodología a distancia tradicional y virtual.

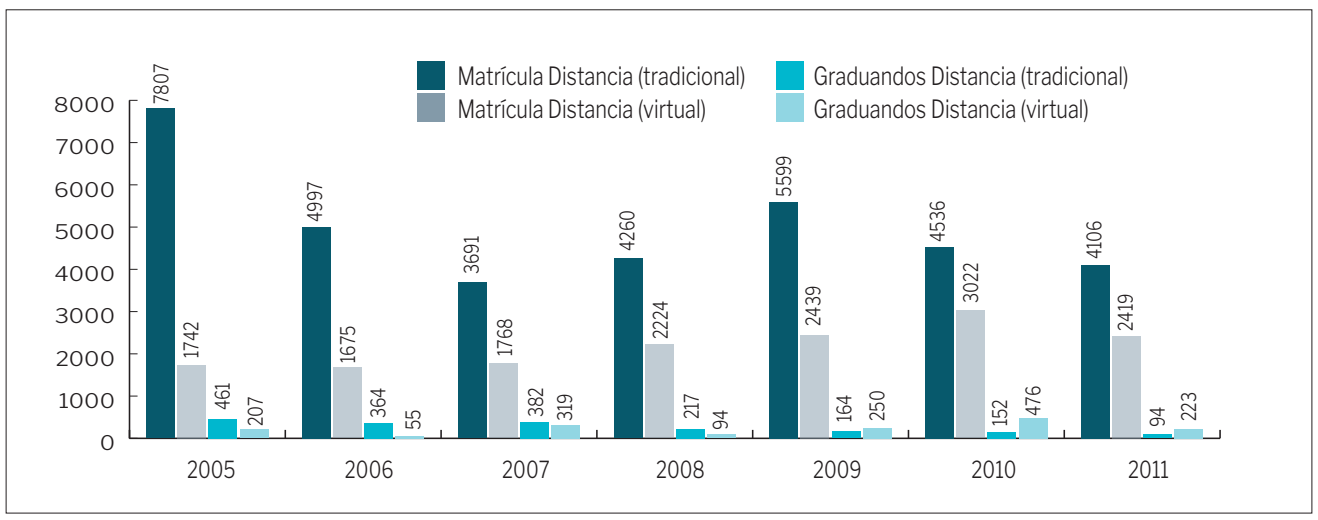

Fuente: Elaboración propia según datos del SNIES corte junio 2012.

En síntesis, se pueden evidenciar tres elementos: 1) que son las IES privadas las que ven una oportunidad de ampliar la cobertura en la educación virtual; 2) que casi la mitad de los programas ofertados corresponden a las áreas como las ciencias administrativas, economías, económicas y afines, seguidas de los programas del área de ingeniería; y 3) las áreas de conocimiento con mayor componente práctico tienen un bajo porcentaje de participación en los programas virtuales de Colombia. Lo anterior puede deberse a la falta de materiales educativos o recursos digitales abiertos y de calidad o la capacitación adecuada tanto de docentes como de estudiantes para programas de estas áreas de conocimiento. El caso es que esta discusión sigue abierta y este estudio no pretende ser concluyente en tal aspecto, en cambió, sí pretende mostrar el análisis de la situación actual de la educación virtual en Colombia, donde la oferta es baja con respecto a los programas presenciales; solo $4.22 \%$ de la oferta total de programas de pregrado y posgrado en Colombia, a pesar del apoyo que ha brindado el Mineducación a través de diferentes convocatorias.

\section{Resultados de la encuesta a IES apoyadas por el Mineducación}

A continuación, se presenta el análisis de los datos de la encuesta realizada a 10 IES que recibieron apoyo del Mineducación a través de las convocatorias abiertas por este órgano del Estado. Esta fase se realizó con apoyo de Renata y el Mineducación entre noviembre y diciembre de 2012 a través del contrato n. ${ }^{0} 738$ de 2012.

Inicialmente, se esperaba un máximo de 17 encuestas diligenciadas de 10 instituciones y se recibieron 9 encuestas relacionadas con 9 instituciones y 11 programas. En la encuesta, se recolectó información relacionada con calidad, pertinencia y cobertura de los programas virtuales, y se presentan solo algunas de las respuestas a las preguntas más relevantes. 


\section{Compromiso institucional}

Frente a las preguntas formuladas a las IES con relación al acompañamiento pertinente de asistencia técnica otorgado por el Mineducación, todas ellas indican que el acompañamiento sí contribuyó para que el programa fuera sostenible y pertinente, además de afirmar que el total de las instituciones tienen políticas enfocadas en el apoyo de programas e-learning y planes tecnológicos, estratégicos y operativos que coadyuvan a la formación virtual. Estos planes y políticas son el primer hito para acceder a la acreditación de alta calidad de los programas virtuales.

Respecto de la vinculación de docentes que apoyan el programa en la institución, se identificó que 66 \% es docente de hora cátedra (figura 1.5), 23 \% es docente de planta y $11 \%$ es docente ocasional de medio tiempo; curiosamente, ninguno de los programas virtuales en las instituciones encuestadas tiene vinculados docentes ocasionales de tiempo completo. Se encontró, además, que 81 \% de los programas tiene docentes con vinculación de cátedra, y en 91 \% de los programas hay docentes de vinculación de planta (10 programas de 11 respuestas), así que tener vinculación de docentes de planta permitirá que el programa crezca y pueda continuar con el proceso de acreditación de alta calidad.

Figura 1.5. Vinculación del cuerpo docente en las IES encuestadas.

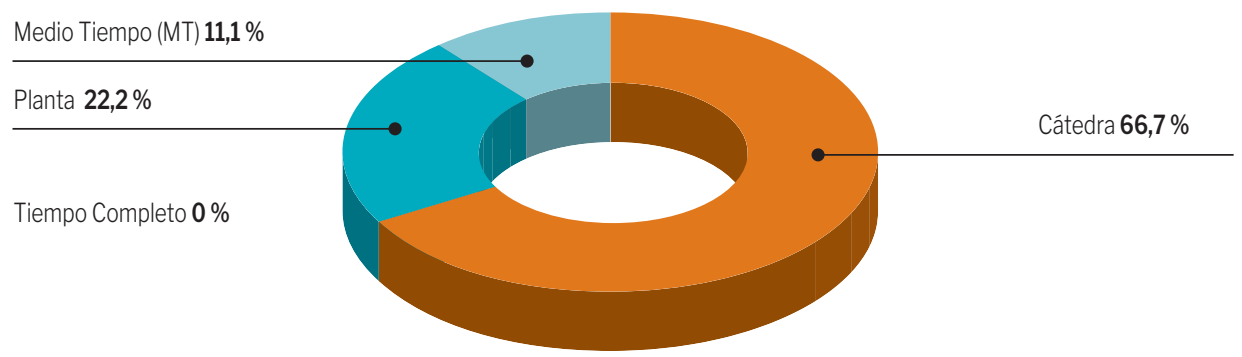

Fuente: Elaboración propia según datos recogidos corte 01/12/2012.

Respecto de la formación de los docentes vinculados que apoyan el programa, se presenta la figura 1.6 con una evidente igualdad en la contratación de docentes con formación en maestría, especialización y profesionales universitarios; sin embargo, se tiene deficiencia en la formación de doctores, pero se sustenta en el hecho de que estos programas encuestados al ser de formación técnica y tecnológica requieren diferentes competencias de aprendizaje a las requeridas en la formación universitaria y de posgrado. 
Comunicación, redes, aprendizaje y desarrollo institucional y social

Figura 1.6. Formación del cuerpo docente en las IES encuestadas.

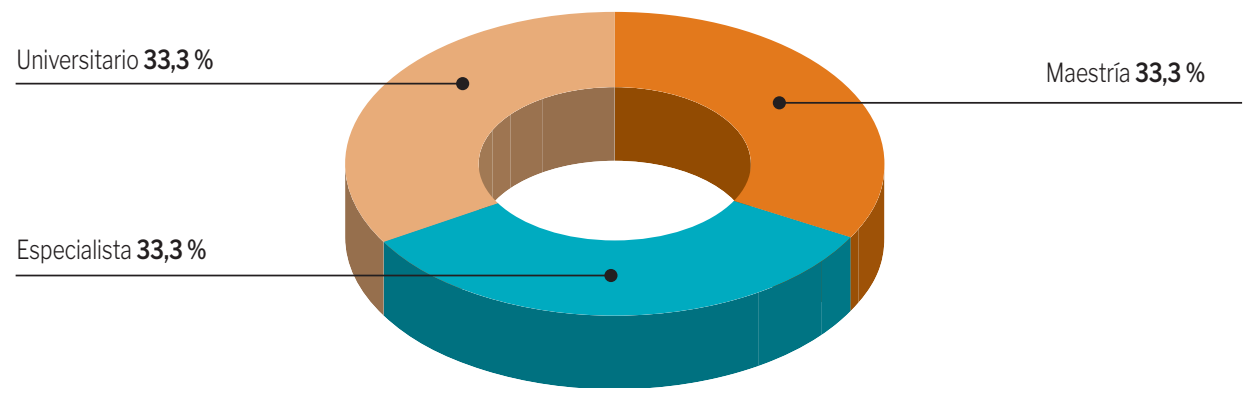

Fuente: Elaboración propia según datos recogidos corte 01/12/2012.

\section{Calidad en servicios institucionales}

Frente a la calidad en servicios institucionales (biblioteca virtual, bienestar universitario, seguimiento a egresados, prácticas o laboratorios virtuales), en general, las respuestas indican que los programas se encuentran en niveles de bueno y aceptable; sin embargo, varias instituciones reconocen su deficiencia en el seguimiento a los egresados. En la figura 1.7, se presenta la distribución de la evaluación hecha por los líderes de los programas de aspectos relacionados con biblioteca virtual o bases de datos digitales, bienestar universitario para estudiantes virtuales, calidad de las prácticas o laboratorios virtuales/remotos provistos por la institución y seguimiento a los egresados del programa. Por otro lado, $100 \%$ de los encuestados manifiesta tener servicios de inscripción y pago en línea, actualización de documentos y aplicación de descuentos para los programas virtuales, lo cual facilita la inscripción de aspirantes interesados en el programa.

Figura 1.7. Evaluación de la calidad en servicios institucionales como biblioteca, bienestar, laboratorios y seguimiento a egresados.

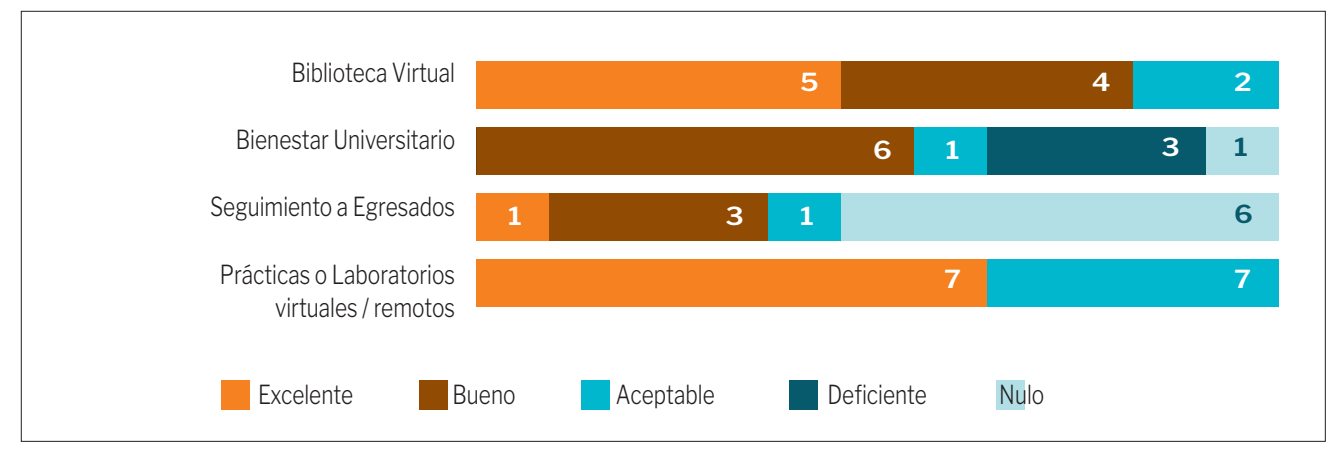

Fuente: Elaboración propia según datos recogidos corte 01/12/2012. 


\section{Calidad en planes de capacitación, convenios y acreditación}

Todas las instituciones capacitan a los administrativos y docentes que apoyan los programas e-learning, lo cual permite mantener vigente y actualizado a los docentes con los cambios que suscita el uso de nuevas tecnologías aplicadas a la educación.

Frente a la frecuencia en las capacitaciones del cuerpo administrativo, siete instituciones respondieron que capacitaban de manera semestral a su cuerpo administrativo, mientras que una lo hacía anual. Las respuestas dadas para la periodicidad en la capacitación del cuerpo docente, seis IES lo hacen de manera semestral, una trimestral y otra anual. Es evidente la inexistencia de una estandarización respecto de la frecuencia de las capacitaciones en el cuerpo académico y administrativo; no obstante, esta disparidad se debe a la autonomía institucional de que gozan las IES en Colombia.

Los temas de capacitación se enfocaron en formación pedagógico-didáctica con 24 \% de las respuestas de los encuestados, seguido de bases de datos digitales con $20 \%$, con $16 \%$ igual para equipos y aplicaciones informáticas y escenarios de simulación virtual y experimentación práctica, 15 \% para tema de recursos bibliográficos y hemeroteca y $9 \%$ para capacitación en laboratorios físicos y remotos (figura 1.8).

Figura 1.8. Temas de capacitación ofrecidos a los docentes.

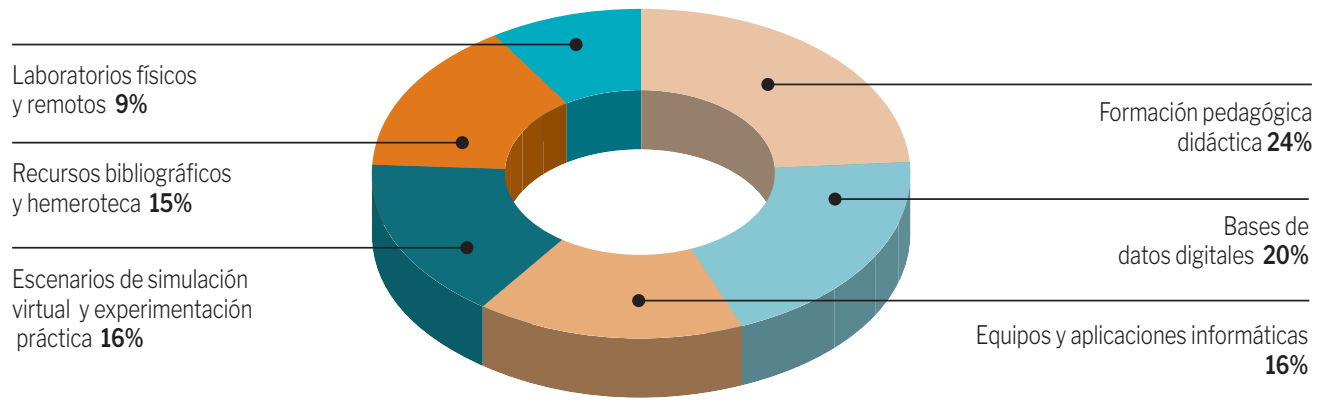

Fuente: Elaboración propia según datos recogidos corte 01/12/2012.

Se preguntó por convenios que apoyaran el funcionamiento de los programas (prácticas, pasantías, intercambios, becas, entre otros), donde solo dos programas de una misma institución tienen convenios; los demás programas carecen de estos. Esta pregunta es impor- 
tante máxime cuando corresponde a uno de los ítems requeridos para la acreditación de alta calidad, lo cual pone de manifiesto la deficiencia existente en la consolidación de redes por parte de las IES y la relación con el sector productivo.

Además, se indagó sobre el número promedio de estudiantes asignados a un docente por curso académico al semestre, y las respuestas variaron entre 10 y 100 estudiantes. Es de resaltar que 7 de las instituciones manifiesta asignar entre 10 y 25 estudiantes, una de ellas indica que no tiene datos dada la carencia de estudiantes y una manifiesta asignar aproximadamente 34 y 100 estudiantes a un docente por curso académico; es necesario indicar que a cada docente le asignan al menos tres o cuatro cursos en un semestre. Lo anterior significa que un número tan elevado de estudiantes por docente, seguramente, dificulta la revisión detallada y realimentación dada a los productos entregados por sus estudiantes, lo cual podría ocasionar debilidad frente a la calidad y el nivel de exigencia de la institución en sus programas virtuales.

\section{Cobertura educativa}

Se indagó en las IES sobre el promedio de estudiantes matriculados en el programa en un semestre, y se obtuvo que un programa no tiene estudiantes matriculados desde hace varios periodos y la respuesta textual fue: "No contamos con estudiantes matriculados en el programa virtual, solo los que terminaron en distancia”. Un programa tiene 511 estudiantes matriculados aproximadamente por semestre y los restantes 9 programas tienen una media de 40 estudiantes matriculados por semestre con una desviación estándar de 11.9. El porcentaje promedio de estudiantes que aprueban los cursos por semestre en todos los programas es de $71 \%$ con una desviación estándar de 15.9 .

Cada semestre existe una población interesada en los programas ofertados de manera virtual y en algunos casos los estudiantes realizan una inscripción o preinscripción en la IES, por lo cual se indagó sobre la proporción de estudiantes que en efecto son admitidos y se matriculan en los programas, frente al interés manifiesto de cursarlo. Se evidenció una alta dispersión de efectividad en la matrícula, la media es de 63 \% con una desviación estándar de 26.7 y donde en 7 de los 11 programas, más de la mitad de los estudiantes que manifiestan estar interesados se matriculan, un programa no registra estudiantes, dos programas registran una matrícula efectiva en $25 \%$ de los casos, un programa en $30 \%$ y uno en $100 \%$. Las causas de la no matrícula se deben a diversos factores que pueden ser estudiados en otro documento.

Frente a la cobertura geográfica las instituciones manifestaron que la mayoría de sus estudiantes son de un área de influencia cercana al lugar donde se realiza la oferta de los 
programas, es decir, son estudiantes que están en la misma zona donde hace presencia la IES, lo cual refuerza que la concentración de la oferta está en las principales ciudades de Colombia.

\section{Pertinencia}

En la figura 1.9, se muestra el grado de percepción de pertinencia de la oferta del programa en la región, respecto de una escala de valor. La autoevaluación es realizada por los líderes de los programas que dieron respuesta a la encuesta, asi $64 \%$ manifiesta que su programa es altamente pertinente, pues cumple con los requerimientos del sector productivo colombiano y sus egresados contribuyen a elevar la competitividad y prosperidad nacional, $27 \%$ lo considera medio alto y $9 \%$ lo considera medio bajo y ninguno lo considera bajo y nulo, donde estos últimos implican que el programa no cumple con los requerimientos del sector productivo o no es pertinente para la región.

En la figura 1.10, se presenta la distribución porcentual de la respuesta que el programa ha brindado para satisfacer las necesidades del medio, donde $46 \%$ de los líderes manifiesta que el programa satisface las necesidades de manera excelente, pues sus egresados se vinculan de manera inmediata al sector productivo satisfaciendo las necesidades, $36 \%$ considera que es bueno pues los egresados tardan menos de doce meses en vincularse al sector productivo, $9 \%$ cree que es aceptable, pues sus egresados tardan entre uno y dos años en vincularse al sector productivo, $9 \%$ de los líderes indica que el programa satisface de manera nula, pero es por la institución que no tiene estudiantes ni egresados, 0 \% lo considera deficiente, y es cuando los egresados tardan más de dos años en vincularse al sector productivo.

Figura 1.9. Grado de percepción de la pertinencia en la oferta del programa.

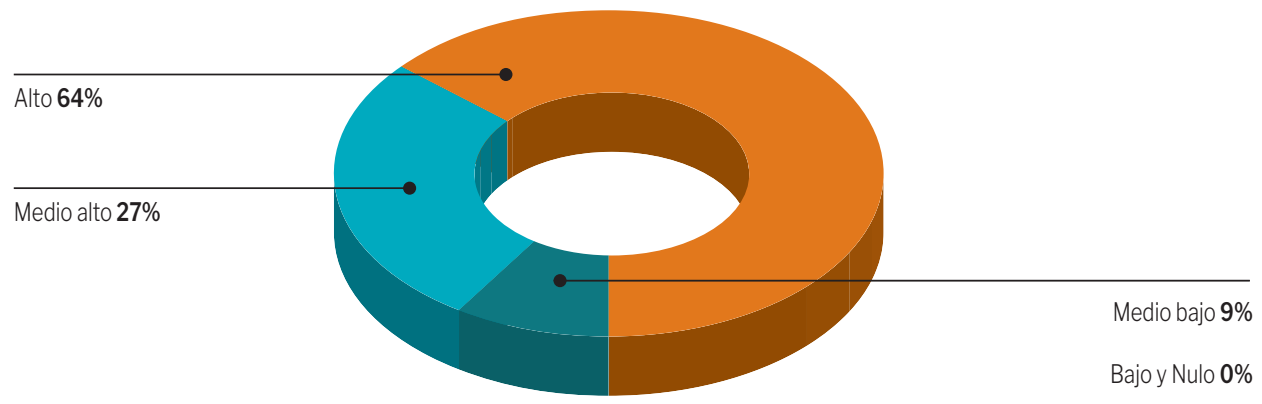

Fuente: Elaboración propia según datos recogidos corte 01/12/2012. 
Comunicación, redes, aprendizaje y desarrollo institucional y social

Figura 1.10. Satisfacción del programa frente a las necesidades del medio.

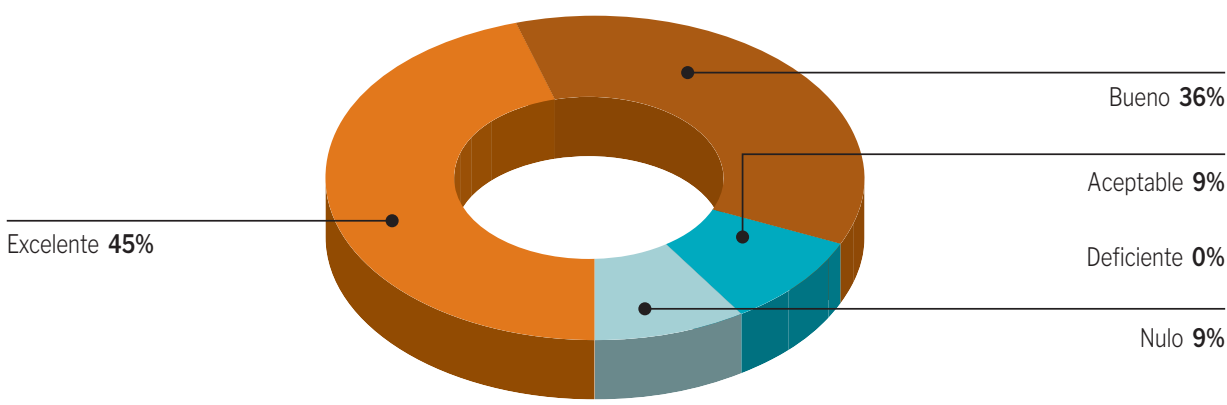

Fuente: Eiáboración propia según diatos recogicios corte 01/122/2012.

\section{Docencia}

Frente a la valoración de los aspectos de docencia, con relación a la experiencia promedio en los docentes que manejan herramientas de formación virtual, herramientas ofimáticas (paquetes procesadores de texto, hojas de cálculo, presentaciones), herramientas telemáticas (internet, correo electrónico, blog, wiki, webquest, herramientas de la web 2.0), sistemas administradores de aprendizaje (LMS como Moodle, Blackboard), entre otros, puede ser de alto a nulo, siendo alto los amplios conocimientos en estas herramientas y nulo los deficientes conocimientos que tienen en el manejo de las herramientas. $Y$ con relación al grado promedio de interacción entre el docente y los estudiantes, se valora de alto a nulo, donde se considera una interacción alta si el docente da respuesta a las inquietudes de los estudiantes en menos de 12 horas, medio alto si el docente da respuesta a las inquietudes de los estudiantes entre 12 y 24 horas, medio bajo si el docente da respuesta a las inquietudes de los estudiantes entre 25 y 48 horas y bajo si el docente da respuesta a las inquietudes de los estudiantes después de 49 horas. En la figura 1.11, se presenta la valoración de los aspectos de docencia, donde en $90 \%$ de las instituciones se considera que sus docentes cumplen en nivel alto y medio alto tanto la experiencia en manejo de herramientas virtuales como en la interacción con sus estudiantes.

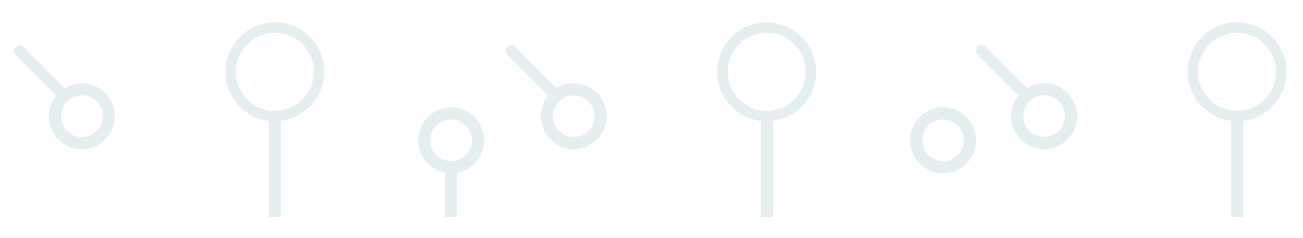


Figura 1.11. Experiencia del docente e interacción con los estudiantes.

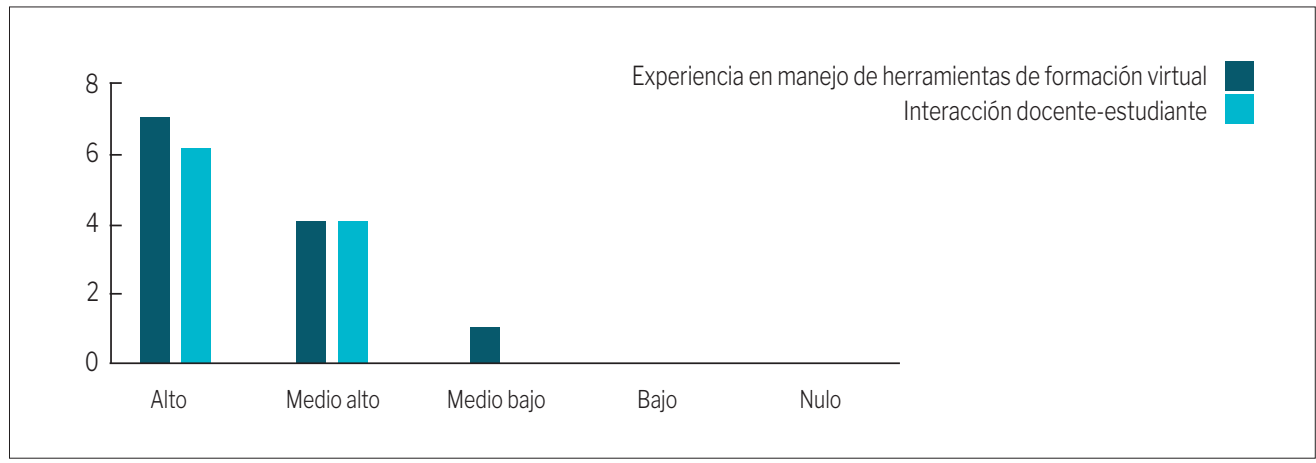

Fuente: Elaboración propia según datos recogidos corte 01/12/2012.

Continuando con la medida de calidad frente a la frecuencia de ingreso de los docentes en los cursos virtuales, los líderes respondieron que aproximadamente $60 \%$ de los docentes ingresa una vez al día, $30 \%$ entre dos y tres veces al día, $10 \%$ tres veces a la semana y $0 \%$ una vez a la semana (figura 1.12). En esta pregunta, una institución no respondió dada la carencia de estudiantes y, por ende, de docentes que acompañan el proceso.

Figura 1.12. Frecuencia promedio de ingreso los cursos virtuales por parte del docente.

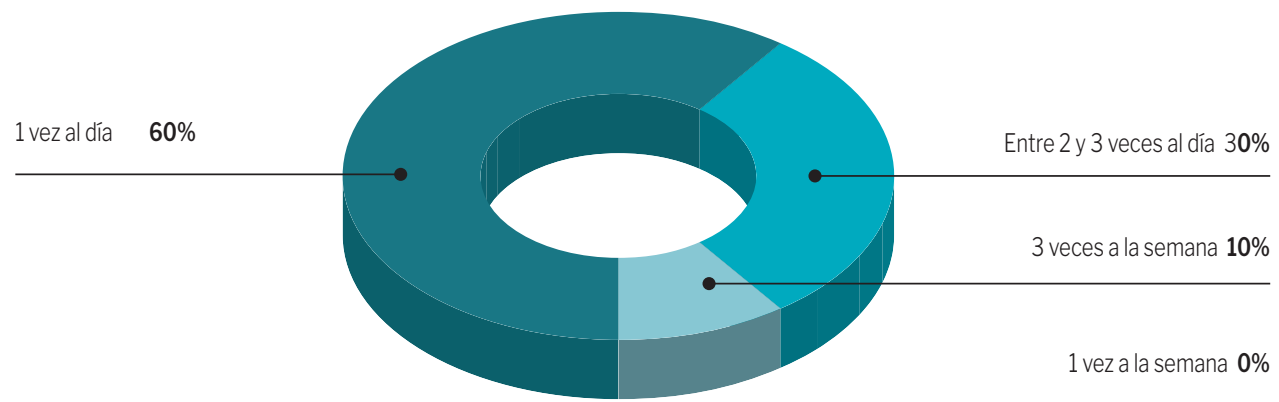

Fuente: Elaboración propia según datos recogidos corte 01/12/2012.

Con relación al fomento a la investigación proporcionado a los estudiantes del programa e-learning por parte de la institución, en la figura 1.13, es evidente que 37 \% de los líderes indica que el fomento a la investigación es medio alto, pues se incita a los estudiantes a la conformación de semilleros y participación en eventos de investigación, mientras que 36 \% lo considera medio bajo, dado que solo fomentan la participación a eventos de investigación, 18 \% señala que es alto, es decir que, aparte de promover la conformación y vinculación a semilleros y eventos, se articula con la pertenencia a grupos de investigación y 9 \% mani- 
fiesta que no se realiza ninguna invitación a labores de investigación, habida cuenta de que los docentes solo orientan el desarrollo disciplinar de los cursos.

Figura 1.13. Fomento en investigación a los estudiantes de los programas virtuales.

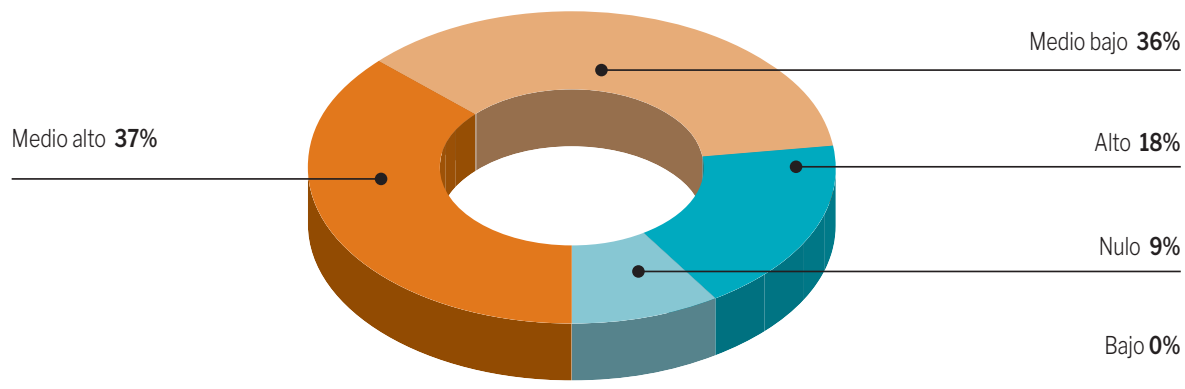

Fuente: Elaboración propia según datos recogidos corte 01/12/2012.

\section{Contenido o material de apoyo del programa}

Al evaluar el tiempo promedio de actualización del material pedagógico-didáctico de los cursos que componen el programa, se encontró que 46 \% de los líderes indica que se actualiza el material con una frecuencia menor de un año (figura 1.14), 36 \% señala que la actualización del material se realiza aproximadamente entre uno y dos años, mientras que $18 \%$ manifiesta que se actualiza entre tres a cinco años.

Asumiendo que cada institución maneja sus propios lineamientos pedagógicos, se consulta si los materiales de apoyo a los cursos son diseñados bajo estas guías, donde $82 \%$ manifiesta que los materiales siempre se diseñan de acuerdo con los lineamientos, $9 \%$ indica que casi siempre se diseña teniendo en cuenta esos parámetros, 9 \% señala que casi nunca usan contenidos diseñados de acuerdo con lineamientos pedagógicos y didácticos adoptados en la institución, es decir, se diseña o se adquiere material que cumpla específicamente con lo disciplinar (figura 1.15). Además, 64 \% considera que el material es de fácil acceso por parte de los estudiantes con una valoración de alto y con una valoración de medio alto lo considera $36 \%$ de los líderes; esta facilidad de acceso está en la disponibilidad de descarga y de consulta en línea de los contenidos.
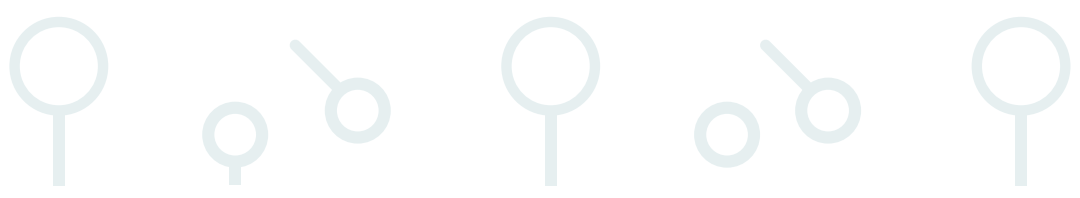
Figura 1.14. Tiempo promedio de actualización de contenidos.

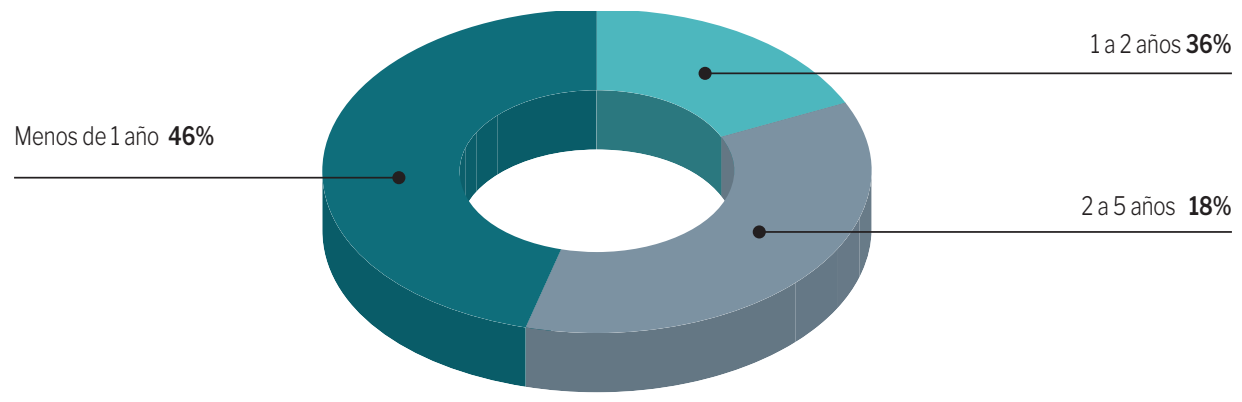

Fuente: Elaboración propia según datos recogidos corte 01/12/2012.

Figura 1.15. Diseño de contenidos de acuerdo con lineamientos pedagógicos y didácticos de la institución.

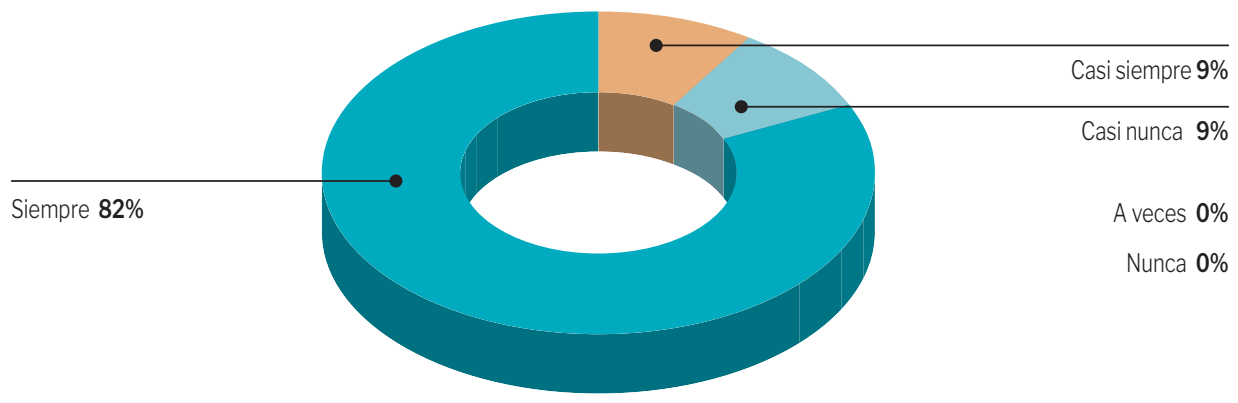

Fuente: Elaboración propia según datos recogidos corte 01/12/2012.

\section{Infraestructura tecnológica}

Se les preguntó a los líderes de los programa sobre la confiabilidad de la plataforma e-learning en cuanto concurrencia, disponibilidad, usabilidad y accesibilidad (figura 1.16). El $73 \%$ valora que la confiabilidad es alta, dado que cumple con la seguridad en contraseñas, soporta el acceso de varios usuarios al tiempo, recibe y reporta entradas y salidas de usuarios, está disponible en cualquier momento y con alta tolerancia a recuperación de fallas y errores resueltos en un tiempo muy corto, es fácil de navegar y usar por cualquier usuario y es accesible con los mínimos recursos computacionales; 9 \% considera que es medio alta, pues cumple con la mayoría de los elementos indicados, mientras que $18 \%$ señala que es medio baja, puesto que cumple con dos o menos de los elementos que la definen confiable. 
Comunicación, redes, aprendizaje y desarrollo institucional y social

Figura 1.16. Confiabilidad de la plataforma e-learning.

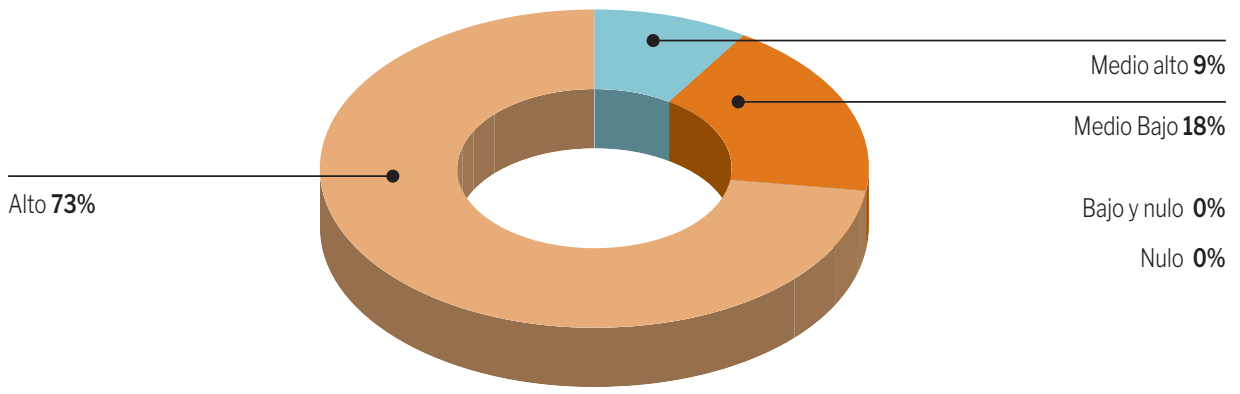

Fuente: Elaboración propia según datos recogidos corte 01/12/2012.

En síntesis, las IES colombianas que ofertan programas virtuales tienen un camino adelantado frente a la implementación de infraestructura tecnológica para uso educativo, por supuesto, aún está en proceso de consolidar y mejorar los aspectos pedagógicos y didácticos que en cierta forma se refleja en los contenidos. Por otro lado, hay indicios de que los apoyos del Gobierno contribuyen a fortalecer de manera temporal las capacidades institucionales para la creación de programas virtuales; no obstante, aunque en la planeación de la oferta de estos programas se tomen el tiempo necesario, aún quedan dudas frente al proceso que se lleva a cabo tanto en la planeación como en la implementación, a la sostenibilidad de los programas al revisar los resultados de las matrículas, a su pertinencia en regiones tan diversas como las que se encuentran en Colombia, cada una con diferentes necesidades, cuando se observa la concentración de oferta de programas de dos áreas de conocimiento y concentración geográfica en cuatro ciudades, además de la debilidad en el seguimiento de los egresados.

\section{Conclusiones}

El panorama presentado es el resultado de un proceso de indagación y reflexión sobre la educación virtual en Colombia que permite tener herramientas para discutir si realmente se cumplen las expectativas en este tipo de formación y si en efecto se lleva a cabo un proceso de gestión y planeación autónomo por parte de las instituciones en la oferta académica o solo son resultados para cumplir con indicadores.

Se evidencia que existe rezago en los estudios de e-learning en Colombia, que inicia desde la legislación que se da ocho años después que se presenta la noción de educación virtual en un plan sectorial de educación y se compila cinco años después sin cambios en los requerimientos para la solicitud de registro calificado (Ley 1188/2008; Decreto 1295/2010; Decreto 1075/2015). Aunque las cifras muestran que en Colombia la educación virtual se 
reconoce como una tendencia, por el crecimiento constante en la oferta de programas virtuales activos, aún es bastante lo que falta por investigar en el tema. Esta demora puede deberse, como se indicó, a que las instituciones están orientadas al cumplimiento de las metas gubernamentales, como este caso, a la creación de programas virtuales, pero no a su sostenibilidad y la verdadera planificación en el futuro.

Si bien existe una relación directa entre los avances de las instituciones educativas en la oferta académica de pregrado y posgrado con las políticas, las metas y los indicadores de un plan de gobierno, desde el Mineducación se reconocen los aprendizajes del acompañamiento a las IES para el fortalecimiento de la capacidad institucional en la oferta de programas virtuales como el cumplimiento de la política. Sin embargo, esto no es suficiente, pues, a partir de este estudio, se identificó que en algunos programas acompañados o asesorados por las convocatorias del Mineducación se presentan deficiencias en cuanto su sostenimiento, número de estudiantes matriculados y real pertinencia en la región.

Por otra parte, se requiere una profunda reflexión sobre la sostenibilidad de los programas académicos virtuales, de su pertinencia, de la relación costo-impacto y de las capacidades institucionales para la puesta en marcha de estas iniciativas. Por lo cual, se propone enriquecer la discusión planteada en este estudio con las opiniones de los estudiantes de las IES involucradas y el sector productivo que emplea a los profesionales egresados de estos programas, de tal manera que se pueda extender el panorama de la educación virtual en Colombia.

Es importante reconocer que, dados los inconvenientes aquí mencionados y otros no expuestos, el crecimiento en la oferta de programas e-learning (por lo menos con $80 \%$ de los cursos virtuales) ha sido sostenido. Según datos del SNIES y del Observatorio de la Universidad Colombiana, para 2010 los programas virtuales correspondían a $1.1 \%$ de la oferta total de programas, para 2012 a $2.53 \%$, para 2014 a $4.17 \%$ y para 2016 fue cerca de $4.97 \%$, aunque siguen siendo bajos con respecto a la oferta de los programas presenciales.

En el mismo sentido del crecimiento, son las IES privadas las que operan un gran porcentaje de los programas virtuales, con 83 \% de participación en 2015, y son estas las que ven en la educación virtual una oportunidad de ampliar la cobertura en la educación superior. Queda por debatir, entonces, la calidad y pertinencia de estos programas, además de verificar su sostenibilidad.

Por otro lado, es causa de indagación por qué no hay cambios en los programas virtuales de las áreas de conocimiento de 1) matemáticas y ciencias naturales y 2) agronomía, veterinaria y afines, dado que su cantidad se mantuvo intacta, mientras que en las otras áreas de conocimiento hubo incrementos en la oferta. 
La infraestructura tecnológica para funcionamiento de la educación virtual está parcialmente superada en Colombia, dado que los equipos iniciales necesarios para soportar este tipo de formación son adquiridos por las IES, incluso, antes de tener una oferta clara o por condiciones de actualización. Cosa muy diferente sucede con la conexión por parte de los estudiantes, que varía dependiendo del operador y de las condiciones geográficas en las cuales se encuentre el estudiante. Por otro lado, lo relacionado con aspectos pedagógicos y didácticos aún está en proceso de consolidación y mejora, al igual que los aspectos culturales y organizacionales, toda vez que, aunque las instituciones tengan un modelo pedagógico propio, en algunos casos, ese modelo pedagógico no se ajusta a las condiciones de los programas virtuales o en otros simplemente los diseñadores no tienen en cuenta el modelo pedagógico de la institución y se basan en el modelo pedagógico que requiera un curso, por lo cual aún es bastante lo que las IES colombianas deben mejorar en este aspecto; por tanto, se deja abierta la discusión y avances en este tema.

\section{Referencias}

Aktaruzzaman, M., Shamim, M. R. y Clement, C. K. (2011). Trends and issues to integrate ICT in teaching and learning for the future world of education. International Journal of Engineering \& Technology, 11(3), 114-119.

Arboleda Toro, N. y Rama Vitale, C. (eds.) (2013). La educación superior a distancia y virtual en Colombia: nuevas realidades. Bogotá: Asociación Colombiana de Instituciones de educación superior con Programas a Distancia y Virtual.

Cabero Almenara, J. (2010). Los retos de la integración de las TICs en los procesos educativos: límites y posibilidades. Perspectiva Educacional, Formación de Profesores, 49(1), 32-61.

Cardona-Román, D. M. y Sánchez-Torres, J. M. (2011). La educación a distancia y el e-learning en la sociedad de la información: una revisión conceptual. Revista UIS Ingenierías, 10(1), 29-52.

Congreso de Colombia. Ley 1753 de 2015. Por la cual se expide el Plan Nacional de DesarroIlo 2014-2018 “Todos por un nuevo país” (9 junio 2015).

DNP (Departamento Nacional de Planeación) (2011). Plan Nacional de Desarrollo 2010-2014. Recuperado de https://www.dnp.gov.co/Plan-Nacional-de-Desarrollo/DNP-2010-2014/ Paginas/Plan-Nacional-De-2010-2014.aspx

DNP (Departamento Nacional de Planeación) (2014). Bases del Plan Nacional de Desarrollo 2014-2018. Recuperado de https://colaboracion.dnp.gov.co/CDT/Prensa/DNP 20142018 Bases Final.pdf

Fedesarrollo (2014). Resumen Plan Nacional de Desarrollo. Recuperado de http://www.fedesarrollo.org.co/wp-content/uploads/Luis-Fernando-Mej\%C3\%ADa-DNP.pdf

Herrera, M. C. (2017). Historia de la educación en Colombia: la República Liberal y la modernización de la educación: 1930-1946. Revista Colombiana de Educación, 26. http://dx.doi. org/10.17227/01203916.26rce\%25p 
Mineducación (Ministerio de Educación Nacional) (2003). La Revolución Educativa: Plan Sectorial Educativo 2002-2006. Recuperado de http://www.mineducacion.gov.co/1621/ articles-85266_archivo_pdf.pdf

Mineducación (Ministerio de Educación Nacional) (2006). Visión: educación propuesta para discusión. Bogotá: Mineducación.

Mineducación (Ministerio de Educación Nacional) (2007). Propuesta de metodología para transformar programas presenciales a virtuales o e-learning. Bucaramanga: MEN. Recuperado de http://wikiplanestic.uniandes.edu.co/lib/exe/fetch.php?media=vision:transformacion_de_presenciales_a_e-learning.pdf

Mineducación (Ministerio de Educación Nacional). Ley 1188 de 2008. Por la cual se regula el registro calificado de los programas de educación superior (25 abril 2008).

Mineducación (Ministerio de Educación Nacional) (2008). Revolucion Educativa: Plan Sectorial Educativo 2006-2010. Recuperado de http://www.mineducacion.gov.co/1621/articles-152025_recurso_1_pdf.pdf

Mineducación (Ministerio de Educación Nacional). Decreto 1295 de 2010. Por el cual se reglamenta el registro calificado de que trata la Ley 1188 de 2008 y la oferta y desarrollo de programas académicos de educación superior (20 abril 2010).

Mineducación (Ministerio de Educación Nacional) (2010a). Lineamientos para la educación virtual en la educación superior. Bogotá: MEN. Recuperado de http://aprende.colombiaaprende.edu.co/ckfinder/userfiles/files/Lineamientos_para_la_educacion_Virtual_ dic_29.pdf

Mineducación (Ministerio de Educación Nacional) (2010b). Revolución Educativa 20022010: acciones y lecciones. Bogotá: MEN. Recuperado de http://www.mineducacion. gov.co/1621/articles-242160_archivo_pdf.pdf

Mineducación (Ministerio de Educación Nacional) (2011). Plan Sectorial educativo 20102014. Bogotá: MEN. Recuperado de http://www.mineducacion.gov.co/1621/articles-293647_archivo_pdf_plansectorial.pdf

Mineducación (Ministerio de Educación Nacional). Decreto 1075 de 2015. Por medio del cual se expide el Decreto Único Reglamentario del Sector Educación (26 mayo 2015).

Misas Arango, G. (2004). La educación superior en Colombia: análisis y estrategias para su desarrollo. Bogotá: Universidad Nacional de Colombia.

Neill, K. O., Singh, G. y Donoghue, J. O. (2004). Implementing e-learning programmes for higher education: A review of the literature. Journal of Information Technology Education, 3, 313-323.

Schneckenberg, D. (2004). El e-learning transforma la educación superior. Educar, 23, 143-156.

Thornburg, D. D. (1999). Technology in K-12 Education: Envisioning a New Future. Recuperado de https://eric.ed.gov/?id=ED452843 